\title{
COMPARAÇÃO ENTRE MÉTODOS PARA A AVALIAÇÃ̃ DO VIGOR DE SEMENTES DE ALGODÃO
}

\section{GABRIEL ELIAS DE SOUZA ${ }^{1}$, FÁBIO STEINER ${ }^{1}$, TIAGO ZOZ ${ }^{1}$, SILVIA SANIELLE COSTA DE OLIVEIRA ${ }^{2}$, SIHÉLIO JÚLIO SILVA CRUZ ${ }^{2}$}

\author{
${ }^{1}$ Departamento de Agronomia - Faculdades Integradas de Ourinhos/MG, Brasil, gabrieleliassouza@hotmail.com, \\ fsteiner_agro@yahoo.com.br, tiago_zoz@hotmail.com. ${ }^{2}$ Instituto Federal Goiano, Rio Verde/GO, Brasil, \\ silviasanielle@bol.com.br, siheliojulio@bol.com.br
}

RESUMO: Em um programa de controle de qualidade, a avaliação do vigor de sementes é fundamental e necessária para o sucesso da produção. Métodos que possibilitam a rápida avaliação do vigor das sementes são de grande interesse no controle de qualidade das empresas produtoras. O objetivo foi avaliar a eficiência de diferentes testes de vigor na avaliação da qualidade fisiológica de sementes de algodão (Gossypium hirsutum L., cv. FM 951LL), buscando a diferenciação de lotes. O estudo foi realizado no Laboratório de Análises de Sementes da Universidade Estadual Paulista - FCA/UNESP, Botucatu-SP, em dezembro de 2011. O delineamento experimental utilizado foi o inteiramente ao acaso com cinco tratamentos e quatro repetições. Cinco lotes de sementes da Cultivar FM 951LL foram submetidos ao teste de germinação (12 dias), primeira contagem (4 dias), teste de germinação a baixa temperatura $\left(18{ }^{\circ} \mathrm{C} / 8\right.$ dias $)$, envelhecimento acelerado $\left(42{ }^{\circ} \mathrm{C} / 72 \mathrm{~h}\right)$, condutividade elétrica (50 sementes/75 mL de água; $25{ }^{\circ} \mathrm{C} / 24 \mathrm{~h}$ ), lixiviação de potássio (50 sementes/100 $\mathrm{mL}$ de água; $25^{\circ} \mathrm{C} / 3 \mathrm{~h}$ ) e teor de água. $\mathrm{O}$ teste de condutividade elétrica, lixiviação de potássio, teste de germinação a baixa temperatura e envelhecimento acelerado são eficientes na avaliação do vigor e diferenciação de lotes de sementes de algodão. No entanto, devido à maior rapidez e facilidade de operação nos laboratórios de análises de sementes, o teste de lixiviação de potássio é alternativa apropriada para a avaliação do vigor de lotes de sementes.

PALAVRAS-CHAVE: Gossypium hirsutum, potencial fisiológico, integridade das membranas, condutividade elétrica, lixiviação de potássio.

\section{COMPARISON OF METHODS FOR ASSESSING THE VIGOR OF COTTON SEEDS}

\begin{abstract}
In a program of seed quality assurance, the evaluation of seed vigor fundamental and necessary to the global production process outcome. Tests allowing quick evaluation of seed vigor are of interest to the seed companies. The objective was to evaluate the efficiency of different vigor tests on evaluation of physiological seed quality of cotton (Gossypium hirsutum L., cv. FM 951LL), seeking the lots differentiation. The study was carried out at the Laboratory of Seed Analysis of the São Paulo State University FCA/UNESP, Botucatu (Sao Paulo State), Brazil, in December 2011. The experimental design was completely randomized with five treatments (seed lots) and four replications. Five cotton seed lots of the cultivar FM 951LL were submitted to the following tests: germination (12 days), first count of germination test (4 days), low temperature germination $\left(18{ }^{\circ} \mathrm{C} / 8\right.$ days), accelerated aging test $\left(42{ }^{\circ} \mathrm{C} / 72\right.$ hours) in distilled water $(100 \% \mathrm{RH})$, electrical conductivity test (50 seeds into $75 \mathrm{~mL}$ of water; at $25^{\circ} \mathrm{C}$ for 24 hours), potassium leaching (50 seeds into $100 \mathrm{~mL}$ of water; at $25^{\circ} \mathrm{C}$ for 3 hours), and also seed water content. Tests of
\end{abstract}


electrical conductivity, potassium leaching, low temperature germination, and accelerated aging were found to be efficient in evaluating cotton seed vigor and in classifying cotton seed lots as to seed vigor. However, due to the greater rapidity, accuracy and convenience of operation and use in the seed analysis laboratories, potassium leaching test is an appropriate alternative for evaluating vigor of the cotton seed lots.

KEY WORDS: Gossypium hirsutum, physiological potential, membrane integrity, electrical conductivity, potassium leaching.

\section{INTRODUÇÃO}

As sementes, após a maturidade fisiológica, passam por processo contínuo e irreversível de deterioração ou envelhecimento. O conhecimento deste processo tem se tornado cada vez mais importante porque é através dele que a pesquisa tem desenvolvido métodos de determinação do potencial fisiológico dos lotes ou vigor de sementes (CUSTÓDIO, 2005).

A avaliação do vigor de sementes é essencial para garantir a qualidade fisiológica das sementes e, consequentemente, do produto a ser fornecido ao agricultor. Esta avaliação auxilia na detecção de problemas durante as operações de colheita, recepção, beneficiamento e comercialização, orientando o produtor nas tomadas de decisões no que concerne a quantidade de semente a ser utilizada e os tratamentos de sementes a serem aplicados. Desta forma, os métodos de determinação da qualidade fisiológica dos lotes de sementes devem possibilitar resultados confiáveis e rápidos, diminuindo os riscos e prejuízos aos envolvidos no setor de tecnologia de produção de sementes (MARCOS FILHO, 2005).

A qualidade fisiológica das sementes é rotineiramente avaliada pelo teste padrão de germinação e testes de vigor. A germinação de lotes de sementes costuma ser similar entre si, por ter que atender à germinação mínima estabelecida pelos padrões de comercialização de sementes (MARTINS; SILVA, 2005; MARCOS FILHO, 2005). Assim, a utilização de lotes com porcentagem de germinação equivalentes entre si, constitui premissa a ser atendida em pesquisas voltadas à verificação da capacidade dos testes de vigor em fornecer dados que, propiciando a diferença qualitativa, permitam a ordenação hierárquica dos lotes, baseadas no potencial fisiológico dos lotes (MARTINS; SILVA, 2005). Portanto, como o teste de germinação apresenta limitações quanto à diferenciação de lotes e demora na obtenção dos resultados, o emprego de testes de vigor que resultam em valores desuniformes entre as avaliações constitui em excelente alternativa para avaliar, com eficiência, a qualidade fisiológica de lotes de sementes, em período de tempo relativamente curto (MARCOS FILHO, 2005).

As pesquisas em tecnologia de sementes têm evidenciado que os testes rápidos de vigor, que produzem informações consistentes, são aqueles relacionados com os processos fisiológicos da deterioração, por exemplo, as atividades enzimáticas e respiratórias e a integridade das membranas celulares, como os testes de condutividade elétrica e de lixiviação de potássio (MIGUEL; MARCOS FILHO, 2002; MIRANDA et al., 2003; MARCOS FILHO, 2005; KIKUTI et al., 2008; ALVES; SÁ, 2010). Estes testes baseiam-se na permeabilidade das membranas, avaliando características relacionadas à liberação de metabólitos durante a embebição das sementes (BARROS; MARCOS-FILHO, 1997). No teste de condutividade elétrica determina-se a quantidade total de íons liberados durante a embebição das sementes, ao passo que, no teste de lixiviação de potássio, quantifica-se somente o íon potássio liberado na solução. O potássio é o principal íon lixiviado pelas sementes durante a embebição e sua liberação tem sido utilizada como indicador da integridade das membranas celulares 
(MIGUEL; MARCOS FILHO, 2002; MIRANDA et al., 2003; MARCOS FILHO, 2005; KIKUTI et al., 2008).

O teste de lixiviação de potássio vem se destacando na avaliação rápida do vigor de sementes, produzindo resultados satisfatórios para algumas espécies como em soja (CUSTÓDIO; MARCOS FILHO, 1997), feijão (BARROS et al., 1999), milho (MIGUEL; MARCOS FILHO, 2002), trigo (FAVARATO et al., 2011), triticale (STEINER et al., 2011) e amendoim (KIKUTI et al., 2008). No entanto, dados referentes ao uso do teste de lixiviação de potássio em sementes de algodão são escassos e incipientes. A determinação de diferenças entre lotes após período de 30 a 120 minutos de embebição das sementes representa uma vantagem do teste de lixiviação de potássio em relação ao teste de condutividade elétrica, pois este necessita de pelo menos 24 horas de embebição para serem realizadas as leituras da condutividade elétrica (MARCOS FILHO, 2005).

Tendo em vista a carência de informações sobre testes de vigor em sementes de algodão, o objetivo foi avaliar a potencialidade dos testes de vigor para avaliação da qualidade fisiológica de lotes de sementes de algodão.

\section{MATERIAL E MÉTODOS}

A pesquisa foi desenvolvida no Laboratório de Análises de Sementes do Departamento de Produção Vegetal da Universidades Estadual Paulista - UNESP, BotucatuSP. Foram utilizados cinco lotes de sementes de algodão (Gossypium hirsutum L.), da cultivar FM 951LL, fornecido pelo Departamento Agronômico da Bayer CropScience. As sementes ficaram armazenadas por 45 dias à $15^{\circ} \mathrm{C}$ e $40 \%$ umidade relativa do ar até o período das análises em Dezembro de 2011. Para a caracterização da qualidade das sementes dos lotes utilizaram-se os testes e determinações, descritos a seguir:

Teor de água das sementes: foi determinado em duas subamostras de 5 gramas de sementes pelo método da estufa a $105^{\circ} \mathrm{C}$ por $24 \mathrm{~h}$ (BRASIL, 2009).

Teste de germinação: foi conduzido com quatro subamostras de 50 sementes por lote, em rolo de papel toalha umedecidos com água destilada, na quantidade equivalente a 2,5 vezes a massa do substrato seco. Em seguida, mantido em câmara com temperatura de $25^{\circ} \mathrm{C}$ sob fotoperíodo de 12 horas, determinando-se a porcentagem de plântulas normais no décimo secundo dia após a instalação do teste (BRASIL, 2009).

Teste de primeira contagem de germinação: realizada conjuntamente com o teste de germinação, registrando-se a porcentagem de plântulas normais no quarto dia após a instalação do teste (BRASIL, 2009).

Teste de envelhecimento acelerado: utilizaram-se quatro subamostras de 50 sementes, as quais foram dispostas em camada única sobre tela de arame em caixa plástica transparente $(11,0 \times 11,0 \times 3,5 \mathrm{~cm})$, contendo $40 \mathrm{~mL}$ de água destilada (100\% UR), mantida a $42{ }^{\circ} \mathrm{C}$ por 72 horas (FREITAS et al., 2000). Em seguida, procedeu-se o teste de germinação com avaliação da porcentagem de plântulas normais no quarto dia após a instalação do teste.

Teste de germinação a baixa temperatura: realizado com quatro subamostras de 50 sementes, em rolos de papel toalha umedecidos com água destilada, na quantidade equivalente a 2,5 vezes a massa do substrato seco, sendo em seguida mantidos à temperatura de $18{ }^{\circ} \mathrm{C}$, no escuro, por 8 dias (DIAS; ALVARENGA, 1999). A avaliação da porcentagem das plântulas normais foi realizada no oitavo dia após a instalação do teste. 
Teste de condutividade elétrica: foram utilizadas quatro subamostras de 50 sementes, onde a massa foi mensurada e colocadas em copos plásticos com $75 \mathrm{~mL}$ de água destilada, em seguida foram mantidas a $25^{\circ} \mathrm{C}$, durante 24 horas. Após esse período, a condutividade elétrica da solução foi determinada em condutivímetro, e os valores médios expressos em $\mu \mathrm{S} \mathrm{cm}^{-1} \mathrm{~g}^{-1}$ de semente (FREITAS et al., 2000).

Teste de lixiviação de potássio: foi realizado utilizando-se quatro subamostras de 50 sementes, cuja massa foi mensurada e colocada em copos plásticos contendo $100 \mathrm{~mL}$ de água destilada, em seguida foram mantidas a $25^{\circ} \mathrm{C}$, por duas horas. Após esse período, a lixiviação de potássio foi determinada em fotômetro de chama. O cálculo da lixiviação de potássio foi feito pela multiplicação da leitura obtida no fotômetro $\left(\mu \mathrm{g} \mathrm{mL} \mathrm{m}^{-1} \mathrm{de} \mathrm{K}\right)$ pelo volume de água destilada $(100 \mathrm{~mL})$ e dividido pela massa de sementes $(\mathrm{g})$. Os resultados foram expressos em $\mu \mathrm{g} \mathrm{mL}^{-1}$ de $\mathrm{K} \mathrm{g}^{-1}$ de semente (MIGUEL; MARCOS FILHO, 2002).

O delineamento experimental utilizado para todos os testes foi o inteiramente casualizado, utilizando quatro repetições para cada tratamento (lote de semente). Os dados obtidos em cada teste foram analisados separadamente através da análise de variância e as médias dos tratamentos foram comparadas pelo teste de Tukey, a 5\% de probabilidade. Realizou-se a determinação dos coeficientes de correlação simples entre os testes, capazes de diferenciar os lotes e a porcentagem de germinação.

\section{RESULTADOS E DISCUSSÃO}

Os teores de água inicial dos lotes de sementes de algodão situaram-se entre 10,0 e 10,2\% (Tabela 1). Esta semelhança de valores é primordial para que os testes não sejam afetados por diferenças na atividade metabólica, velocidade de umedecimento e na intensidade de deterioração das sementes. Recomenda-se que não haja diferenças superiores a $2 \%$ de teor de água das sementes das amostras antes do envelhecimento (MARCOS FILHO, 2005).

Tabela 1. Resultados do teor de água das sementes (TA), teste de germinação $(\mathrm{G})$, primeira contagem da germinação (PCG), teste de germinação a baixa temperatura (TB), envelhecimento acelerado (EA), condutividade elétrica (CE) e lixiviação de potássio (LK) dos 5 lotes de sementes de algodão (Gossypium hirsutum L., cv. FM 951LL). Botucatu - SP, 2011

\begin{tabular}{cccccccc}
\hline Lote & TA & G & PCG & TB & EA & CE & LK \\
\hline & $-----0^{\dagger}$ & $91 \mathrm{a}$ & $89 \mathrm{a}$ & $56 \mathrm{a}$ & $76 \mathrm{a}$ & $252 \mathrm{a}$ & $136 \mathrm{a}$ \\
$\mathrm{A}$ & 10,2 & $91 \mathrm{a}$ & $90 \mathrm{a}$ & $58 \mathrm{a}$ & $70 \mathrm{a}$ & $281 \mathrm{ab}$ & $143 \mathrm{a}$ \\
$\mathrm{B}$ & 10,2 & $89 \mathrm{a}$ & $87 \mathrm{a}$ & $51 \mathrm{a}$ & $53 \mathrm{~b}$ & $275 \mathrm{ab}$ & $144 \mathrm{a}$ \\
$\mathrm{C}$ & 10,1 & $86 \mathrm{a}$ & $84 \mathrm{a}$ & $40 \mathrm{~b}$ & $48 \mathrm{~b}$ & $308 \mathrm{bc}$ & $163 \mathrm{~b}$ \\
$\mathrm{D}$ & 10,0 & $86 \mathrm{~mL}^{-1} \mathrm{~K} \mathrm{~g}^{-1}$ & \\
$\mathrm{E}$ & 10,1 & $85 \mathrm{a}$ & $78 \mathrm{a}$ & $41 \mathrm{~b}$ & $55 \mathrm{~b}$ & $344 \mathrm{c}$ & $158 \mathrm{~b}$ \\
\hline $\mathrm{CV}(\%)$ & 0,8 & 9,3 & 10,3 & 11,2 & 12,8 & 6,5 & 4,3 \\
\hline
\end{tabular}

${ }^{\dagger}$ As médias seguidas da mesma letra na coluna não diferem entre si, pelo teste de Tukey a 5\% de probabilidade.

Os lotes de sementes de algodão apresentaram porcentagem de germinação semelhantes (Tabela 1) e superiores ao mínimo (75\%) estabelecido pelos padrões para comercialização de sementes de algodão (BRASIL, 2005). Essas características são importantes para a confiabilidade dos resultados do presente trabalho, pois os testes de vigor devem ser capazes de detectar diferenças no potencial fisiológico de lotes, principalmente dos 
que possuem poder germinativo semelhante (MARTINS; SILVA, 2005; COIMBRA et al., 2009).

De acordo com a Tabela 1, todos os testes de vigor utilizados foram eficientes em diferenciar lotes de maior ou menor vigor, com exceção do teste de primeira contagem, que não diferenciou os lotes quanto ao vigor.

$\mathrm{O}$ teste de condutividade elétrica separou os lotes em quatro classes de vigor: alto (lote A), médio alto (lotes B e C), médio baixo (lote D) e baixo (lote E). O teste de germinação a baixa temperatura, envelhecimento acelerado e lixiviação de potássio permitiram agrupar os lotes em duas classes, de maior e menor vigor. Em geral, estes três testes classificaram os lotes $\mathrm{A}, \mathrm{B}$ e C como de maior vigor e os lotes $\mathrm{D}$ e $\mathrm{E}$ como de menor vigor, exceto para o teste de envelhecimento acelerado que classificou o lote $\mathrm{C}$ como de menor vigor (Tabela 1).

Os trabalhos de pesquisa têm apresentado dificuldades de identificação de lotes com níveis intermediários de vigor, pois dependendo do teste utilizado, esses lotes podem apresentar comportamento próximo aos de alto ou baixo vigor (STEINER et al., 2011). Desta forma, um teste de vigor pode ser considerado eficiente quando detecta diferenças entre lotes de alto e baixo vigor ou qualidade fisiológica de sementes (MIGUEL; MARCOS FILHO, 2002; MARCOS FILHO, 2005; MARTINS; SILVA, 2005).

A menor variação entre as repetições para os resultados de lixiviação de potássio em comparação ao teste de condutividade elétrica indica maior reprodutibilidade e facilidade na padronização do teste de lixiviação para sementes de algodão (Tabela 1). Adicionalmente, a obtenção dos resultados do teste de lixiviação de potássio em somente duas horas quando comparado ao período superior a 24 horas necessário para os demais testes, atende a uma das principais exigências das empresas de sementes: a avaliação eficiente e rápida da qualidade das sementes, de modo a permitir a tomada de decisões quanto às operações de colheita, processamento e comercialização (MARCOS FILHO, 2005).

De modo similar ao verificado neste trabalho, para outras espécies como amendoim, triticale e rúcula, a avaliação do íon potássio liberado durante a embebição das sementes resultou em melhores índices de avaliação de vigor do que o total dos eletrólitos liberados obtidos pelo teste de condutividade elétrica (KIKUTI et al., 2008; ALVES; SÁ, 2010; STEINER et al., 2011).

Todos os testes utilizados para aferir o vigor das sementes de algodão se correlacionaram com a porcentagem de germinação; teste usado como referência (Tabela 2). Para os dados obtidos na condutividade elétrica e lixiviação de potássio houve correlação negativa com a porcentagem de germinação e demais testes de vigor. Estes resultados indicam que aumentos na quantidade de metabólitos liberados durante o processo de embebição das sementes corresponderam a reduções na porcentagem de germinação e do vigor das sementes, devido à menor integridade das membranas celulares verificado em lotes de menor vigor (MIGUEL; MARCOS FILHO, 2002; MIRANDA et al., 2003; MARCOS FILHO, 2005; KIKUTI et al., 2008; ALVES; SÁ, 2010).

Houve correlação significativa entre a maioria dos testes de vigor utilizados, exceto: entre o teste de primeira contagem da germinação e envelhecimento acelerado e entre o teste de envelhecimento acelerado e condutividade elétrica (Tabela 2). No entanto, a correlação indica apenas tendência de variação semelhante entre duas características orientando-nos que para uma análise mais adequada da eficiência dos testes de vigor, deve-se realizar a comparação das médias dos lotes para cada teste avaliado (MARCOS FILHO, 2005; BRAZ; ROSSETO, 2009; COIMBRA et al., 2009; ALVES; SÁ, 2010). 
Tabela 2. Coeficientes de correlação simples entre os parâmetros do teste de germinação (G), primeira contagem da germinação (PCG), teste de germinação a baixa temperatura (TB), envelhecimento acelerado (EA), condutividade elétrica (CE) e lixiviação de potássio (LK) dos 5 lotes de sementes de algodão (Gossypium hirsutum L., cv. FM 951LL). Botucatu - SP, 2011

\begin{tabular}{llllll}
\hline & PCG & TB & EA & CE & LK \\
\hline G & $0,94^{* *}$ & $0,98^{* *}$ & $0,79^{*}$ & $-0,91^{* *}$ & $-0,93^{* *}$ \\
PCG & $0,88^{*}$ & 0,61 & $-0,92^{* *}$ & $-0,77^{*}$ \\
TB & & $0,80^{*}$ & $-0,83^{*}$ & $-0,94^{* *}$ \\
EA & & & $-0,67$ & $-0,82^{*}$ \\
CE & & & & $0,86^{*}$ \\
\hline *e e*: significativo ao nível de 5\% e 1\% pelo teste F, respectivamente.
\end{tabular}

\section{CONCLUSÃO}

O teste de condutividade elétrica, lixiviação de potássio, teste de germinação a baixa temperatura e envelhecimento acelerado são eficientes na avaliação do vigor e diferenciação do potencial fisiológico de lotes de sementes de algodão. No entanto, devido à maior rapidez e facilidade de operação em laboratórios de análises de sementes, o teste de lixiviação de potássio é alternativa apropriada para a avaliação do vigor de lotes de sementes.

\section{REFERÊNCIAS BIBLIOGRÁFICAS}

ALVES, C. Z.; SÁ, M. E. Avaliação do vigor de sementes de rúcula pelo teste de lixiviação de potássio. Revista Brasileira de Sementes. Londrina-PR, v. 32, n. 2, p. 108-116, 2010.

BARROS, M. A.; OHSE, S.; MARCOS FILHO, J. Ion leakage as an indicator of vigor in field bean seeds. Seed Technology, Lansinhg, v. 21, n. 1, p. 44-48, 1999.

BARROS, A. S. R.; MARCOS-FILHO, J. Testes para avaliação rápida do vigor de sementes de soja. Revista Brasileira de Sementes, Brasília-DF, v. 19, n. 2, p. 289-295, 1997.

BRASIL. MINISTÉRIO DA AGRICULTURA, PECUÁRIA E ABASTECIMENTO. Padrões para produção e comercialização de sementes de algodão. Instrução normativa n.25, de 16 de dezembro de 2005. Diário Oficial da União, sec.1, n. 243, p.18 de 20/12/2005, 2005.

BRASIL. MINISTÉRIO DA AGRICULTURA, PECUÁRIA E ABASTECIMENTO. Secretaria de Defesa Agropecuária. Regras para análise de sementes. 2009. 399 p.

BRAZ, M. R. S.; ROSSETTO, C. A. V. Correlação entre testes para avaliação da qualidade de sementes de girassol e emergência das plântulas em campo. Ciência Rural, Santa MariaRS, v. 39, n. 7, p. 2004-2009, 2009.

COIMBRA, R. A.; MARTINS, C. C.; TOMAZ, C. A.; NAKAGAWA J. Testes de vigor utilizados na avaliação da qualidade fisiológica de sementes de milho-doce. Ciência Rural, Santa Maria-RS, v. 39, n. 9, p. 2402-2408, 2009.

CUSTÓDIO, C. C. Testes rápidos para avaliação do vigor de sementes: uma revisão. Colloquium Agrariae, Presidente Prudente-SP, v. 1, n. 1, p. 29-41, set. 2005.

CUSTÓDIO, C. C.; MARCOS FILHO, J. Potassium leakage test for the evaluation of soybean seed physiological quality. Seed Science and Technology, Zurich, v. 25, n. 3, p. 549-564, 1997. 
DIAS, D. C. F. S.; ALVARENGA, E. M. Teste de germinação a baixa temperatura. In: KRZYZANOWSKI, F. C.; VIEIRA, R. D.; FRANÇA NETO, J. B. (Ed.). Vigor de sementes: conceitos e testes. Londrina-PR: ABRATES, 1999. p. 71-74.

FAVARATO, L. F.; ROCHA, V. S.; ESPINDULA, M. C.; SOUZA, M. A.; PAULA, G. S. Teste de lixiviação de potássio para avaliação da qualidade em sementes de trigo. Revista Brasileira de Ciências Agrárias, Londrina-PR, v. 6, n. 4, p. 670-674, 2011.

FREITAS, R. A.; DIAS, D. C. F. S.; REIS, M. S.; CECON, P. R. Correlação entre testes para avaliação da qualidade de sementes de algodão e a emergência das plântulas em campo. Revista Brasileira de Sementes, Londrina-PR, v. 22, n. 1, p. 97-103, 2000.

KIKUTI, H.; MEDINA, P. F.; KIKUTI, A. L. P.; RAMOS, N. P. Teste de lixiviação de potássio para avaliação do vigor de sementes de amendoim. Revista Brasileira de Sementes, Londrina-PR, v. 30, n. 1, p. 10-18, 2008.

MARCOS FILHO, J. Fisiologia de sementes de plantas cultivadas. Piracicaba-SP: Fealq, 2005. 495 p.

MARTINS, L.; SILVA, W. R. Interpretação de dados obtidos em testes de vigor para a comparação qualitativa entre lotes de sementes de milho. Revista Brasileira de Sementes, Londrina-PR, v. 27, n. 1, p. 19-30, 2005.

MIGUEL, M. V. C.; MARCOS FILHO, J. Potassium leakage and maize seed physiological potential. Scientia Agrícola, Piracicaba-SP, v. 59, n. 2, p. 315-319, 2002.

MIRANDA, D. M.; NOVEMBRE, A. D. L. C.; CHAMMA, H. M. C. P.; MARCOS FILHO, J. Avaliação do potencial fisiológico de sementes de pimentão pelo teste de lixiviação de potássio. Informativo ABRATES, Londrina-PR, v. 13, n. 3, p.275, 2003.

STEINER, F.; OLIVEIRA, S. S. C.; MARTINS, C. C.; CRUZ, S. J. S. Comparação entre métodos para a avaliação do vigor de lotes de sementes de triticale. Ciência Rural, Santa Maria-RS, v. 41, n. 2, p. 200-204, 2011. 